\title{
An artificial neural network model for prediction of quality characteristics of apples during convective dehydration
}

Karina DI SCALA ${ }^{1,2 *}$, Gustavo MESCHINO ${ }^{3}$, Antonio VEGA-GÁLVEZ Roberto LEMUS-MONDACA ${ }^{4}$, Sara ROURA ${ }^{1,2}$, Rodolfo MASCHERONI ${ }^{2,5,6}$

\begin{abstract}
In this study, the effects of hot-air drying conditions on color, water holding capacity, and total phenolic content of dried apple were investigated using artificial neural network as an intelligent modeling system. After that, a genetic algorithm was used to optimize the drying conditions. Apples were dried at different temperatures $\left(40,60\right.$, and $\left.80{ }^{\circ} \mathrm{C}\right)$ and at three air flow-rates $(0.5,1$, and $1.5 \mathrm{~m} / \mathrm{s})$. Applying the leave-one-out cross validation methodology, simulated and experimental data were in good agreement presenting an error $<2.4 \%$. Quality index optimal values were found at $62.9^{\circ} \mathrm{C}$ and $1.0 \mathrm{~m} / \mathrm{s}$ using genetic algorithm.
\end{abstract}

Keywords: artificial neural networks; quality attributes; genetic algorithm; process optimization; dried apple.

\section{Introduction}

Dehydration is one of the most commonly used methods for fruit preservation. Its main objective aiming to improve the shelf life of foods is to reduce fruit moisture content to such extent that microorganisms cannot grow and deterioration reactions are minimized. However, it is well known that during convective hot-air drying, foods undergo physical, structural, chemical, and nutritional changes that can affect quality attributes like texture, color, flavor, and nutritional value (VEGA-GÁLVEZ et al., 2009). The current degree of acceptance of dehydrated foods in the market can be further expanded with improvements in product quality and process applications. Therefore, consumers demand for healthy products requires the simulation and further optimization of the drying conditions to minimize detrimental quality changes that occur during processing (DI SCALA; CRAPISTE, 2008).

Artificial neural networks (ANN) are recognized as good tools for dynamic modeling. ANN modeling methods do not require parameters of physical models and have the ability to learn from experimental data. Furthermore, they are capable of handling complex systems with nonlinearities and interactions between decision variables, such as drying processes (CHEN; RAMASWAMY; ALLI, 2001; JINDAL; CHAUHAN, 2001; LERTWORASIRIKUL; TIPSUWAN, 2008; MOVAGHARNEJAD; NIKZAD, 2007; CHEGINI et al., 2008; TRIPATHY; KUMAR, 2009; FATHI; MOHEBBI; RAZAVI, 2011; KHOSHHAL et al., 2010). The multi-layer perceptron (MLP) is one of the most commonly ANN type used in food engineering problems (CHEN; RAMASWAMY; ALLI, 2001; MOVAGHARNEJAD; NIKZAD, 2007; HERNÁNDEZPÉREZ et al., 2004).
On the other hand, the genetic algorithm (GA) is one of the search methods and optimization techniques used for determining the optimal value of a complex objective function by simulation of the biological evolutionary process based, as in genetics, on crossover and mutation (FATHI; MOHEBBI; RAZAVI, 2011; DAM; SARAF, 2006; SHOPOVA; VAKLIEVABANCHEVA, 2006; ERENTURK; ERENTURK, 2007; POONNOY; TANSAKUL; CHINNAN, 2007).

GA offers several advantages over the conventional optimization method such as less susceptibility to be stuck at local minima, requiring little knowledge of the process being optimized and capability to find the optimum conditions when the search space is very large (FATHI; MOHEBBI; RAZAVI, 2011).

Therefore, the aim of this study were to develop an ANN to estimate quality index values of apples during convective hot-air drying and find the optimal process conditions that minimize product quality loss using GA based on a multiobjective function.

\section{Materials and methods}

\subsection{Raw material and drying conditions}

Apples (Granny Smith) were purchased from a local market in the municipality of La Serena (Chile). They were hand-washed, and the stems were removed. Then, they were cut into cylindrical pieces with a diameter of $20 \pm 0.2 \mathrm{~mm}$ and 5.00.2 $\mathrm{mm}$ of thickness. Hot-air drying process was carried

\section{Received $17 / 5 / 2012$}

Accepted 5/7/2013 (005700)

${ }^{1}$ Food Engineering Research Group, Universidad Nacional de Mar del Plata - UNMdP, Mar del Plata, Buenos Aires, Argentina

${ }^{2}$ Consejo Nacional de Investigaciones Científicas y Técnicas - CONICET, Av. Rivadavia, 1917, C1033AAJ, Ciudad Autónoma de Buenos Aires, Argentina,

e-mail: kdiscala@fi.mdp.edu.ar

${ }^{3}$ Laboratory of Bioengineering, Universidad Nacional de Mar del Plata - UNMdP, Mar del Plata, Buenos Aires, Argentina

${ }^{4}$ Department of Food Engineering, Universidad de La Serena - ULS, La Serena, Chile

${ }^{5}$ Centro de Investigación y Desarrollo en Criotecnología de Alimentos - CIDCA, Centro Científico Tecnológico - CCT, Consejo Nacional de Investigaciones Científicas y

Tecnológicas - CONICET, Universidad Nacional de La Plata - UNLP, La Plata, Buenos Aires, Argentina

${ }^{6}$ Facultad Ingeniería - MODIAL, Universidad Nacional de La Plata - UNLP, La Plata, Buenos Aires, Argentina

${ }^{*}$ Corresponding author 
out in a convective dryer (Figure 1) designed and built at the Department of Food Engineering of Universidad de La SerenaChile (VEGA-GÁLVEZ et al., 2009). The air temperature and flow rate were 40,60 , and $80{ }^{\circ} \mathrm{C}$ and $0.5,1$, and $1.5 \mathrm{~m} / \mathrm{s}$, respectively. A raw material load density of $10.2 \mathrm{Kg} / \mathrm{m}^{2}$ was used. The experiments were finished at the point of reaching constant weight (equilibrium condition). Dried samples were packaged in polypropylene bags for further quality analysis.

\subsection{Experimental design}

The conditions applied in the experimental setups used for the drying of apples are based on a factorial design $n^{m}$, in which $n$ is the number of levels and $m$ is the number of factors. Air-drying temperature and velocity were the two factors under study $(m=2)$, each with three levels $(n=3)$. Thus, 9 treatments were required. Table 1 shows the experimental design used to represent the experiments.

\subsection{Measurements of quality index values}

\section{Surface color $(\Delta E)$}

The colors of apple samples were measured using a colorimeter (HunterLab, MiniScan ${ }^{\mathrm{TM}} \mathrm{XE}$ Plus, Reston, VA, USA). Color was expressed in CIE $L^{*}$ (whiteness or brightness), $a^{*}$ (redness/greenness), and $b^{*}$ (yellowness/ blueness) coordinates, standard illuminant $\mathrm{D}_{65}$, and observer $10^{\circ}$ (VEGA-GÁLVEZ et al., 2009). Five replicate measurements

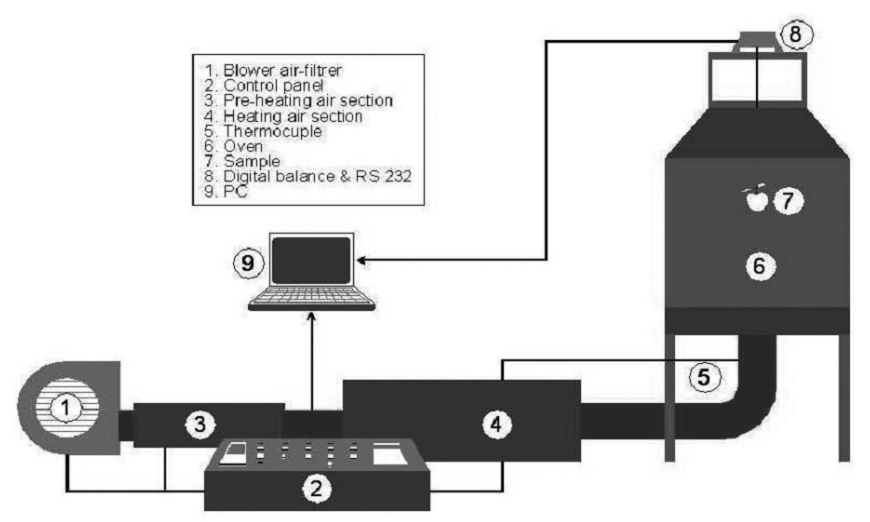

Figure 1. Drying equipment schematic diagram.

Table 1. Treatments applied to fresh apples.

\begin{tabular}{ccc}
\hline Treatments & Air temperature $\left({ }^{\circ} \mathrm{C}\right)$ & Air velocity $(\mathrm{m} / \mathrm{s})$ \\
\hline T1 & 40 & 0.5 \\
T2 & 40 & 1.0 \\
T3 & 40 & 1.5 \\
T4 & 60 & 0.5 \\
T5 & 60 & 1.0 \\
T6 & 60 & 1.5 \\
T7 & 80 & 0.5 \\
T8 & 80 & 1.0 \\
T9 & 80 & 1.5 \\
\hline
\end{tabular}

were performed, and the results were averaged. The total color difference $(\Delta E)$ was calculated using Equation 1, where $L_{\mathbf{o}}, a_{\mathbf{0}}$, and $b_{\mathrm{o}}$ are the control values for fresh apple.

$\Delta E=\left[\left(a^{*}-a_{0}\right)^{2}+\left(b^{*}-b_{0}\right)^{2}+\left(L *-L_{0}\right)^{2}\right]^{0.5}$

\section{Total phenolic content (TPC)}

TPC was determined using the the Folin-Ciocalteau reagent (FC) according to Chuah et al. (2008) with modifications. An aliquot of $0.5 \mathrm{~mL}$ of the fruit extract solution was transferred to a glass tube and $0.5 \mathrm{~mL}$ of reactive $\mathrm{FC}$ was added after 5 minutes; an aliquot of $2 \mathrm{~mL}$ of $\mathrm{Na}_{2} \mathrm{CO}_{3}$ solution $\left(200 \mathrm{mg} \mathrm{mL}^{-1}\right)$ was added, and the solution was shaken. The sample was then mixed using a vortex mixer, and the reaction proceeded for 15 minutes at ambient temperature. Next, $10 \mathrm{~mL}$ of ultra-pure water were added, and the precipitate formed was removed by centrifugation for 5 minutes at $4000 \mathrm{xg}$. Finally, absorbance was measured using a spectrophotometer (Spectronic 20 GenesysTM131, Illinois, USA) at $725 \mathrm{~nm}$ and compared to a gallic acid (GA) calibration curve. The results were expressed as mg GAE/ 100 gdry matter. All reagents were purchased from Merck (Merck KGaA, Darmstadt, Germany). All measurements were performed in triplicate.

\section{Water holding capacity (WHC)}

The dried apple slabs were placed in distilled water at $40^{\circ} \mathrm{C}$ for 6 hours, using a solid to liquid ratio of 1:50. The Water Holding Capacity was calculated from the amount of water removed following Equation 2, according to a previous study by Vega-Gálvez et al. (2009).

$$
W H C=\frac{W_{r e h} * X_{r e h}-W_{l}}{W_{r e h} * X_{r e h}} * 100
$$

where $\mathrm{W}_{\text {reh }}$ is the weight of the sample after the rehydration process, $\mathrm{X}_{\text {reh }}$ is the moisture content of the sample after the rehydration process on a wet matter, and $\mathrm{W}_{1}$ is the weight of the drained liquid after centrifugation. The WHC was expressed as $\mathrm{g}$ retained water $/ 100 \mathrm{~g}$ water. All measurements were performed in triplicate.

\subsection{ANN and optimization model}

\section{The Multi Layer Perceptron}

An artificial neural network is a set of basic units interconnected in an adequate way. The basic processing unit in the MLP (also known as feed forward networks) is the neuron. Every neuron receives signals from the input or other neurons through weighted connections. The signals are then weightedadded together before being applied to a transfer function to produce the output. The output signals are then propagated to other neurons until the output of the network is reached. For approximation tasks (i.e. mapping input vectors with output vectors), the MLP often has one hidden layer of neurons with sigmoid transfer functions followed by an output layer of 
neurons with linear transfer functions (JINDAL; CHAUHAN, 2001; HERNÁNDEZ-PÉREZ et al., 2004).

\section{Neural network error estimation: Leave-One-Out}

To estimate the error of the network, Leave-One-Out (LOO) cross-validation (PICARD; COOK, 1984) was applied. As the name suggests, LOO cross-validation involves the using of a single observation at a time from the original sample as the test data, and the remaining observations as the training data. This is repeated as many times as the number of data samples so that it assures that each observation in the sample is used once as test data. LOO process is usually very expensive from a computational point of view because of the number of times the training process is repeated. However, it is not a limitation in this case study application because of the small number of data available (ZOLLANVARI; BRAGA-NETO; DOUGHERTY, 2009).

LOO cross-validation has been shown to give an almost unbiased estimator of the generalization properties of statistical models, and therefore it provides a sensible criterion for model selection and comparison (ANCONA et al., 2005).

\section{Genetic algorithms}

GAs have been demonstrated to be appropriate tools for parameter optimization tasks, and they have been produced good results. GA is a search technique used to find good solutions to optimization and search problems. They belong to a particular class of evolutionary algorithms that use techniques inspired by evolutionary biology such as reproduction, inheritance, mutation, and selection. The problem to solve, usually a set of parameters to find, is coded as a vector, named an individual. The selection criterion is based on the fitness function. The fitness function plays the role of the environment to distinguish between good and bad solutions (SHOPOVA; VAKLIEVA-BANCHEVA, 2006). The GA creates an initial population (a set of initial solutions). This population will change due to the reproduction of individuals in the successive iterations. Occasionally, with some low probability, mutations will make changes in some individuals. The best individuals are selected so that each population will be better than the previous one. For the GA setting, some configurations must be determined, such as the population size, selection, reproduction and mutation methods, probability of mutation, stopping criteria, etc. (SHOPOVA; VAKLIEVA-BANCHEVA, 2006; ERENTURK; ERENTURK, 2007).

\section{Proposed model and numerical resolution}

A neural network having two inputs (air temperature and air flow rate), a hidden layer, and three outputs (color, total polyphenols content, and water holding capacity) was proposed. This network makes the mapping between inputs and output values. Once trained, it can give output values for new input values not included in the training set.

In order to find the number of neurons in the hidden layer, a typical learning error as a function of neurons number in the hidden layer was plot (data not shown). It has been shown that taking the training error into consideration is enough for this choice.

Validation of the net (the process that can assure the generalization ability) was carried out using the leave-one-out approach. After training the net, a multi-objective GA was used to find the optimal drying conditions using the MLP model. The GA conducted the search of good values for the air temperature and air flow rate trying to minimize color, maximize total polyphenols content, and maximize water holding capacity, simultaneously. The neural networks as well as the optimization were developed using Matlab 7.8 software with Neural Network Toolbox Version 6, Genetic Algorithm, and Direct Search Toolbox Version 2.4.1 (Mathworks, Natick, MA).

The fit quality was evaluated using the Relative Error (RE, Equation 3) and the linear correlation coefficient $\left(r^{2}\right.$, Equation 4), which compares the values predicted by the artificial neural networks and the experimental data.

$R E(\%)=\frac{\phi_{\exp }-\phi_{c a l c}}{\phi_{\max }-\phi_{\min }} \times 100$

$r^{2}=\sum_{i=1}^{N} \frac{\left(\varphi_{\text {cal }, i}-\bar{\varphi}_{\mathrm{exp}, i}\right)}{\left(\varphi_{\mathrm{exp}, i}-\bar{\varphi}_{\mathrm{exp}, i}\right)^{2}}$

where $\phi_{\exp }$ is experimental quality data and $\phi_{\text {cal }}$ is ANNpredicted quality data.

\section{Results and discussion}

\subsection{Drying characteristics}

Figure 2 shows the drying curves for the three temperatures at air velocities of $0.5,1.0$, and $1.5 \mathrm{~m} / \mathrm{s}$. A clear influence of air drying temperature on the drying kinetics of the apple slabs can

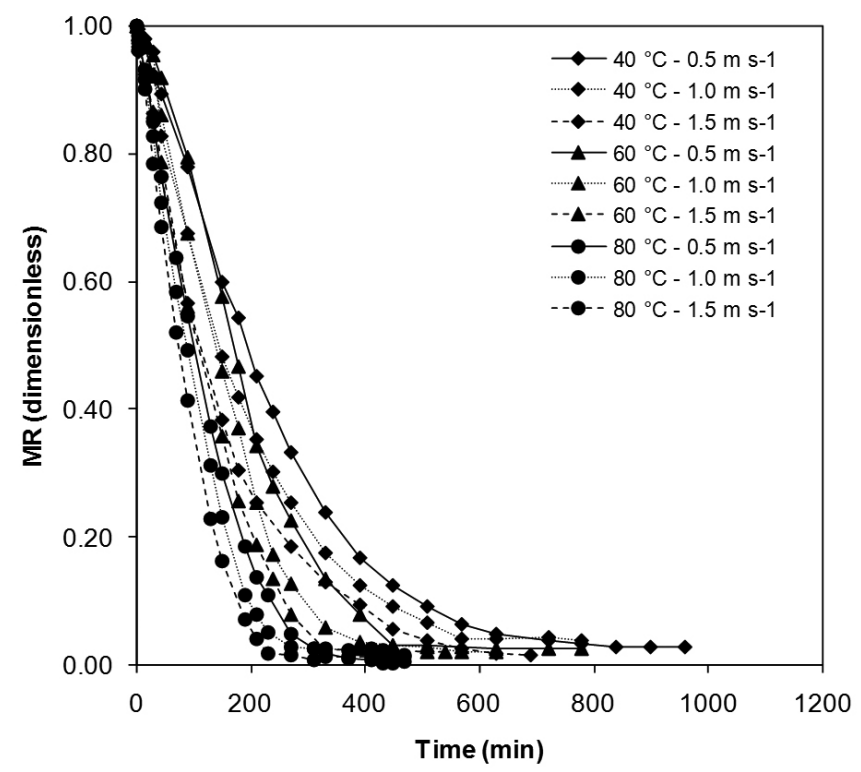

Figure 2. Drying curves at air temperatures of 40,60 , and $80^{\circ} \mathrm{C}$ for three different air velocities. 
be observed. An increase in the drying temperature resulted in a decrease in the drying time. The time needed to achieve equilibrium moisture content in all experiments was between 200 and 1000 minutes. Comparable results were reported by other authors working with different fruits (VELIĆ et al., 2004; LEMUS-MONDACA et al., 2009; URIBE et al., 2011). Drying time is the longest at $40^{\circ} \mathrm{C}$ and at air velocity of $0.5 \mathrm{~m} \mathrm{~s}^{-1}(\mathrm{~T} 1)$, while the shortest drying time occurred at $80{ }^{\circ} \mathrm{C}$ and at air velocity of $1.5 \mathrm{~m} \mathrm{~s}^{-1}$ (T9).

\subsection{Quality parameters}

Table 2 shows the experimental color difference $(\Delta \mathrm{E})$ values for all drying treatments. Chromatic coordinates for fresh apples were $82.9 \pm 0.99,0.64 \pm 0.25$, and $21.4 \pm 0.58$ for $\mathrm{L}$, a, and $\mathrm{b}$, respectively. At constant air-drying velocity, $\Delta \mathrm{E}$ decreased with air-drying temperatures. Long drying times due to low process temperature could promote apple discoloration associated to formation of browning products. When analyzing the trend of $\Delta \mathrm{E}$ at constant temperature, an increase in high air-drying velocity was observed $\left(1.5 \mathrm{~ms}^{-1}\right)$; however, this increment was not significant $(\mathrm{p}<0.05)$. It is also noticeable that treatments $\mathrm{T} 7, \mathrm{~T} 8$, and $\mathrm{T} 9$ showed the lowest values of $\Delta \mathrm{E}$. Changes in $\Delta \mathrm{E}$ are brought about by simultaneous heat and mass transfer occurring at the surface of the apple samples and depended on the drying time and temperature. Only slight differences in $\Delta \mathrm{E}$ were observed among the values obtained at the three different temperatures. At $40{ }^{\circ} \mathrm{C}$, a prolonged processing time is observed in contrast to a higher heat flow at $80^{\circ} \mathrm{C}$, and in both cases browning was favored; at $60^{\circ} \mathrm{C}$, a decrease in both drying time and heat energy resulted in a weaker color change. Although at $60^{\circ} \mathrm{C}$ heat energy increased under drying at $40^{\circ} \mathrm{C}$, processing time reduced to such an extent that less browning took place. At an air velocity of $1.0 \mathrm{~m} \mathrm{~s}^{-1}$ the acting convective forces did not seem to be able to reduce the effect of heat energy and moisture accumulation at the surface of the samples. The effect of drying time was enough to cause a substantial color change at 40 and $60^{\circ} \mathrm{C}$; at $80^{\circ} \mathrm{C}$; this effect was even enhanced by a higher heat flow.

Table 3 shows the total phenolic content of the dehydrated apple samples. The initial TPC of the fresh sample was $158.28 \pm 0.65 \mathrm{mg} \mathrm{GAE} / 100 \mathrm{~g}$ sample. It was observed that an

Table 2. Experimental and ANN-predicted surface color for rehydrated-dried apples.

\begin{tabular}{cccc}
\hline \multirow{2}{*}{ Treatment } & \multicolumn{2}{c}{$\Delta \mathrm{E}$} & \multirow{2}{*}{ \%Relative error } \\
\cline { 2 - 3 } & Experimental & Predicted & \\
\hline T1 & $35.70 \pm 0.18$ & $35.71 \pm 0.18$ & 0.72 \\
T2 & $29.10 \pm 0.93$ & $29.10 \pm 0.93$ & 4.55 \\
T3 & $37.17 \pm 0.10$ & $37.17 \pm 0.10$ & 0.38 \\
T4 & $28.15 \pm 0.04$ & $28.15 \pm 0.04$ & 0.23 \\
T5 & $28.89 \pm 0.40$ & $28.89 \pm 0.40$ & 1.99 \\
T6 & $33.88 \pm 0.48$ & $33.88 \pm 0.48$ & 2.01 \\
T7 & $18.75 \pm 0.33$ & $45.15 \pm 0.93$ & 2.51 \\
T8 & $19.96 \pm 0.98$ & $18.89 \pm 0.53$ & 5.31 \\
T9 & $27.04 \pm 0.53$ & $27.04 \pm 0.53$ & 2.77 \\
\hline
\end{tabular}

increase in drying temperature caused degradation of total phenolics with respect to corresponding content in the fresh sample $(\mathrm{p}<0.05)$. Prolonged drying time did not necessarily produce the strongest degradation (T1); a temperature rise is needed to cause degradation of total phenolics. The experimental results showed that TPC decreased with increasing temperature at air drying velocities of 0.5 and $1.0 \mathrm{~m} \mathrm{~s}^{-1}$, as observed in the treatments T1-T4-T7 and T2-T5-T8. However, this tendency changed completely as air-drying velocity was increased to $1.5 \mathrm{~m} \mathrm{~s}^{-1}$. At $80^{\circ} \mathrm{C}$, the highest drying temperature, degradation of total phenolics is the lowest. This is probably due to high convective forces acting on the air-solid interface retarding heat diffusion into the solid apples. Internal resistance to heat diffusion is therefore an important parameter to be considered when quality is at stake during heat treatment in the drying process of apples. Increasing correlation between antioxidant activity and total phenolic content has been reported during food dehydration. However, data of the effects of drying on TPC and antioxidant activity of fruits are rather conflicting due to several factors such as the drying method, the type of extraction solvent, the antioxidant assays, and the interactions of several antioxidant reactions (MANZOCCO et al., 2001).

It can be seen in Table 4, the WHC changes as the air temperature increased at a constant air velocity $(p<0.05)$. At constant air velocity of $1.5 \mathrm{~m} \mathrm{~s}^{-1}$, the difference in WHC obtained for the three temperatures is less pronounced. The maximum

Table 3. Experimental and ANN-predicted total phenolic content for rehydrated-dried apples.

\begin{tabular}{cccc}
\hline \multirow{2}{*}{ Treatment } & \multicolumn{2}{c}{ TPC $(\mathrm{mg}$ GAE/100 g d.m. } & \multirow{2}{*}{ \%Relative error } \\
\cline { 2 - 3 } & Experimental & Predicted & \\
\hline T1 & $31.93 \pm 0.96$ & $31.93 \pm 0.96$ & 4.27 \\
T2 & $27.39 \pm 1.30$ & $27.39 \pm 1.30$ & 6.71 \\
T3 & $27.34 \pm 0.48$ & $27.34 \pm 0.48$ & 2.50 \\
T4 & $40.15 \pm 0.63$ & $40.15 \pm 0.63$ & 2.22 \\
T5 & $39.31 \pm 0.55$ & $39.31 \pm 0.55$ & 2.00 \\
T6 & $33.62 \pm 0.22$ & $33.62 \pm 0.22$ & 0.93 \\
T7 & $38.70 \pm 0.44$ & $38.70 \pm 0.44$ & 1.62 \\
T8 & $44.82 \pm 0.18$ & $44.82 \pm 0.18$ & 0.58 \\
T9 & $44.12 \pm 1.20$ & $44.12 \pm 1.20$ & 5.66 \\
\hline
\end{tabular}

Table 4. Experimental and ANN-predicted water holding capacity for rehydrated-dried apples.

\begin{tabular}{cccc}
\hline \multirow{2}{*}{ Treatment } & \multicolumn{2}{c}{ WHC $(\mathrm{g}$ retained water/100g water $)$} & \multirow{2}{*}{ \%Relative error } \\
\cline { 2 - 3 } & Experimental & Predicted & \\
\hline T1 & $45.15 \pm 1.93$ & $45.15 \pm 1.80$ & 2.91 \\
T2 & $56.30 \pm 6.04$ & $56.30 \pm 5.29$ & 0.74 \\
T3 & $50.94 \pm 3.68$ & $50.94 \pm 4.06$ & 2.95 \\
T4 & $51.66 \pm 4.08$ & $51.66 \pm 5.13$ & 0.35 \\
T5 & $53.74 \pm 2.12$ & $53.74 \pm 1.49$ & 2.45 \\
T6 & $44.12 \pm 4.76$ & $44.12 \pm 4.89$ & 3.85 \\
T7 & $48.28 \pm 2.23$ & $48.28 \pm 2.55$ & 1.30 \\
T8 & $45.46 \pm 5.98$ & $45.46 \pm 5.72$ & 2.11 \\
T9 & $47.80 \pm 2.79$ & $47.80 \pm 2.39$ & 2.35 \\
\hline
\end{tabular}




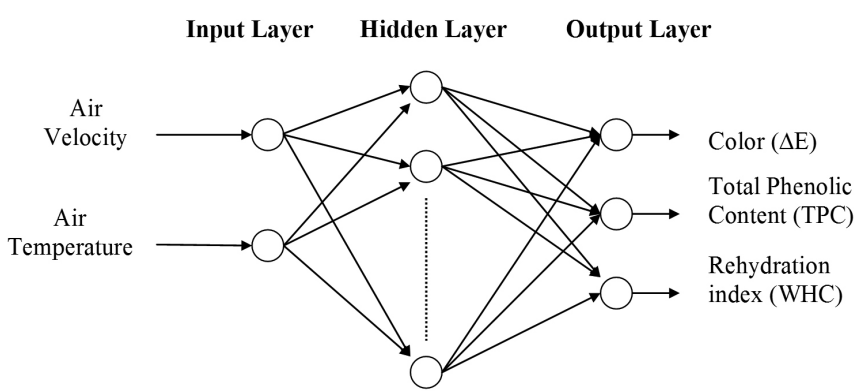

Figure 3. Scheme of neural network of the multilayer perceptron type.

WHC was $56.30 \pm 0.01 \mathrm{~g}$ retained water $/ 100 \mathrm{~g}$ water obtained in treatment $\mathrm{T} 4$, which implies that this drying temperature caused the greatest tissue structure damage; thus, apples dehydrated under this drying condition retain a great amount of water. On the other hand, samples dried in T1, T6, and T8 reduced WHC, hence complete rehydration of the dried product was not achieved.

\subsection{ANN modeling}

Figure 3 shows the structure of the proposed network (2-25-3). The transfer function in the hidden layer was of a sigmoid type, while a linear transfer function (purelin) was used in the output layer (TRIPATHY; KUMAR, 2009). A learning (or training) algorithm is defined as a procedure that consists of adjusting the coefficients (weights and biases) of a network to minimize an error function between the network outputs for a given set of inputs and the right outputs already known (HERNÁNDEZ-PÉREZ et al., 2004). Thus, by error analysis, 25 nodes were selected in the hidden layer resulting in an error value of $2.4 \%$. Tables 2,3 , and 4 show the quality index values simulated by the net together with experimental data for test database of the apples. The maximum relative error for $\Delta \mathrm{E}$ was $6.11 \%$, for TPC it was $5.66 \%$, and for WHC it was $4.63 \%$. When plotting experimental quality data against ANN-predicted quality parameters (Figures not shown) for each of the quality parameters analyzed, the linear correlation coefficients between those values were: $r^{2}=0.987$ for $\Delta E ; r^{2}=0.990$ for TPC, and $r^{2}=0.994$ for WHC. The values of $r^{2}$ together with the relative errors shown in Tables 2, 3, and 4 demonstrated the goodness of the proposed ANN. Comparable results were reported in previous investigations. The application of ANN has shown to be a useful tool for prediction of quality parameters in previous investigations on dehydration of other fruits such as blueberries (CHEN; RAMASWAMY; ALLI, 2001); orange juice (CHEGINI et al., 2008), and pumpkin (ZENOOZIAN et al., 2008).

In order to optimize the process, a multi-objective function was used to find optimal drying conditions using the MLP model. This multi-objective function took into account the three quality parameters studied. Therefore, using the GA methodology, optimal values of 26.37 of $\Delta \mathrm{E}, 42.05$ [mg GAE/100 $\mathrm{g} \mathrm{d}$. m.] of $\mathrm{TPC}$, and 51.61 [g retained water $/ 100 \mathrm{~g}$ water] of WHC were found at $62.9{ }^{\circ} \mathrm{C}$ and $1.0 \mathrm{~m} / \mathrm{s}$. Thus, under these optimal processing conditions, one would expect the best quality product within the imposed constraints.

\section{Conclusions}

A feed-forward neural network model for predicting color and functional properties of apples during drying $\left(40-80{ }^{\circ} \mathrm{C}\right.$ and $0.5-1.0 \mathrm{~m} / \mathrm{s}$ ) was studied in this investigation. The Leave-one-out cross validation error was applied resulting in a $2.4 \%$ error. A multi-objective Genetic Algorithm was coupled with the configuration of neural network to find optimal drying conditions. Optimal values of 26.37 of $\Delta \mathrm{E}, 42.05$ [mg GAE/100 g d. m.] of TPC, and 51.61 [g retained water $/ 100 \mathrm{~g}$ water] of WHC were found at $62.9^{\circ} \mathrm{C}$ and $1.0 \mathrm{~m} / \mathrm{s}$. The results indicated that the hybrid ANN-GA model could be effectively used not only to estimate the quality index values of dehydrated apples, but also to identify optimal drying conditions.

\section{Acknowledgements}

The authors gratefully acknowledge the Agencia Nacional de Promoción Científica y Tecnológica (ANPCyT), under Project PICT07-001107, and the Consejo Nacional de Investigaciones Científicas y Técnicas (CONICET) from Argentina, under Project PIP 0007, for the financial support.

\section{References}

ANCONA, A. et al. Leave-one-out prediction error of systolic arterial pressure time series under paced breathing. Physiological Measurements, v. 26, n. 4, p. 363-72, 2005. PMid:15886432. http:// dx.doi.org/10.1088/0967-3334/26/4/003

CHEGINI, G. R. et al. Prediction of process and product parameters in an orange juice spray dryer using artificial neural networks. Journal of Food Engineering, v. 84, p. 534-543, 2008. http://dx.doi. org/10.1016/j.jfoodeng.2007.06.007

CHEN, C. R.; RAMASWAMY, C. H.; ALLI, I. Prediction of quality changes during osmo- convective drying of blueberries using neural network models for process optimization. Drying Technology, v. 19 , n. $3-4$, p. 507-523, 2001. http://dx.doi.org/10.1081/DRT100103931

CHUAH, A. M. et al. Effect of cooking on the antioxidant properties of coloured peppers. Food Chemistry, v. 111, p. 20-28, 2008. http:// dx.doi.org/10.1016/j.foodchem.2008.03.022

DAM, M.; SARAF, D. Design of neural networks using genetic algorithm for on-line property estimation of crude fractionator products. Computers and Chemical Engineering, v. 30, p. 722729, 2006. http://dx.doi.org/10.1016/j.compchemeng.2005.12.001

DI SCALA, K.; CRAPISTE, G. Drying kinetics and quality changes during drying of red pepper. LWT- Food Science and Technology, v. 41, n. 5, p. 789-795, 2008.

ERENTURK, S.; ERENTURK, K. Comparison of genetic algorithm and neural network approaches for the drying process of carrot. Journal of Food Engineering, v. 78, p. 905-912, 2007. http://dx.doi. org/10.1016/j.jfoodeng.2005.11.031

FATHI, M.; MOHEBBI, M.; RAZAVI, S. Effect of Osmotic Dehydration and air drying on physicochemical properties of dried kiwifruit and modeling of dehydration process using neural network and genetic algorithm. Food and Bioprocess Technology, v. 4, n. 8, p. 1519-1526, 2011. http://dx.doi.org/10.1007/s11947-010-0452-Z

HERNÁNDEZ-PÉREZ, J. A. et al. Neural networks for the heat and mass transfer prediction during drying of cassava and mango. 
Innovative Food Science and Emerging Technologies, v. 5, p. 57-64, 2004. http://dx.doi.org/10.1016/j.ifset.2003.10.004

JINDAL, V. K.; CHAUHAN, V. Neural Networks Approach to Modeling Food Processing Operations. In: IRUDAYARAJ, J. (Ed.). Food Processing Operations Modeling. Marcel Dekker, Inc., 2001.

KHOSHHAL, A. et al. Artificial neural network modeling of apple drying process. Journal of Food Process Engineering, v. 33, p. 298313, 2010. http://dx.doi.org/10.1111/j.1745-4530.2009.00435.x

LEMUS-MONDACA, R. et al. Dehydration characteristics of papaya (Carica pubenscens): determination of equilibrium moisture content and diffusion coefficient. Journal of Food Process Engineering, v. 32 , n. 5 , p. $645-663,2009$. http://dx.doi.org/10.1111/j.17454530.2007.00236.x

LERTWORASIRIKUL, S.; TIPSUWAN, Y. Moisture content and water activity prediction of semi-finished cassava crackers from drying process with artificial neural network. Journal of Food Engineering, v. 84, n. 1, p. 65-74, 2008. http://dx.doi.org/10.1016/j. jfoodeng.2007.04.019

MANZOCCO, L. et al. Review of enzymatic browning and antioxidant capacity in processed foods. Trends in Food Science and Technology, v. 11, p. 340-346, 2001. http://dx.doi.org/10.1016/ S0924-2244(01)00014-0

MOVAGHARNEJAD, K.; NIKZAD, M. Modeling of tomato drying using artificial neural network. Computers and Electronics in Agriculture, v. 59, p. 78-85, 2007. http://dx.doi.org/10.1016/j. compag.2007.05.003

PICARD, R. R.; COOK, R. D. Cross-Validation of Regression Models. Journal American Statistical Association, v. 79, n. 387, p. 575583, 1984. http://dx.doi.org/10.1080/01621459.1984.10478083

POONNOY, P.; TANSAKUL, A.; CHINNAN, A. Estimation of Moisture Ratio of a Mushroom Undergoing Microwave-vacuum
Drying Using Artificial Neural Network and Regression Models. Chemical Product and Process Modeling, v. 2, n. 3, p. 1-13, 2007. http://dx.doi.org/10.2202/1934-2659.1057

SHOPOVA, E.; VAKLIEVA-BANCHEVA, N. BASIC-A genetic algorithm for engineering problems solution. Computers and Chemical Engineering, v. 30, p. 1293-1309, 2006. http://dx.doi. org/10.1016/j.compchemeng.2006.03.003

TRIPATHY, P. P.; KUMAR, S. Neural network approach for food temperature prediction during solar drying. International Journal of Thermal Sciences, v. 48, p. 1452-1459, 2009. http://dx.doi. org/10.1016/j.ijthermalsci.2008.11.014

URIBE, E. et al. Characteristics of Convective Drying of Pepino Fruit (Solanum muricatum Ait.): Application of Weibull Distribution. Food Bioprocess Technology, v. 4, n. 8, p. 1349-1356, 2011. http:// dx.doi.org/10.1007/s11947-009-0230-y

VEGA-GÁLVEZ, A. et al. Effect of air-drying temperature on physicochemical properties, antioxidant capacity, colour and total phenolic content of red pepper (Capsicum annuum, L. var. Hungarian). Food Chemistry, v. 117, p. 647-653, 2009. http://dx.doi.org/10.1016/j. foodchem.2009.04.066

VELIĆ, D. et al. Influence of airflow velocity on kinetics of convection apple drying. Journal of Food Engineering, v. 64, p. 97-102, 2004. http://dx.doi.org/10.1016/j.jfoodeng.2003.09.016

ZENOOZIAN, S. et al. Use of Artificial Neural Network and Image Analysis to Predict Physical Properties of Osmotically Dehydrated Pumpkin. Drying Technology, v. 26, p. 132-144, 2008. http://dx.doi. org/10.1080/07373930701781793

ZOLLANVARI, A.; BRAGA-NETO, U. M.; DOUGHERTY, E. R. On the sampling distribution of resubstitution and leave-one-out error estimators for linear classifiers. Pattern Recognition, v. 42, p. 2705-2723, 2009. http://dx.doi.org/10.1016/j.patcog.2009.05.003 